\title{
J ob satisfaction and career development of men in nursing
}

\author{
Geraldine Ann Moore', J acqueline A. Dienemann² \\ 1. Molloy College, New York, United States. 2. University of North Carolina Charlotte, Charlotte, United States. \\ Correspondence: Geraldine Ann Moore. Address: Molloy College, United States. Email: gmoore@molloy.edu
}

Received: July 30, 2013

Accepted: September 17, 2013 Online Published: November 1, 2013

DOI : $10.5430 /$ jnep.v4n3p86

URL: http://dx.doi.org/10.5430/jnep.v4n3p86

\section{Abstract}

Background: Men are a growing minority in nursing. A deeper understanding of their motivation, career paths, and job satisfaction is needed to target recruitment and retention efforts. Currently the largest male cohort entering nursing is by second career. This study examines if job satisfaction differs for men who choose nursing as their first choice of career, as a convenience after exploring other options, or as a second career.

Methods: This mixed-method study examined the relationship between men entering nursing by choice, convenience or second career and their resultant job satisfaction. A convenience sample of 238 men answered an online survey. Entry path, current practice position, and future career plans in five years was by self report. Job satisfaction was measured using Lester's instrument.

Results: Second career men were significantly more likely to work in specialty practice and more likely to aspire to advanced practice than those entering by choice or convenience early in their careers. No significant differences in job satisfaction were found between entry paths.

Conclusions: These data raise provocative issues relating to recruiting men and the impact of men on the profession of nursing. Despite the steady but slow growth in the percent of men in nursing, its image remains overwhelmingly female. This survey does not identify substantial differences in job satisfaction between men who enter through different career paths or substantial differences with other studies of male and female nurses.

\section{Key words}

Male registered nurses, Job satisfaction, Career development

\section{I ntroduction}

Men who become nurses are aware they are choosing to enter a women's profession and will need to cope with sexual stereotypes held by society and themselves. Despite this apparent barrier, the percentage of men in nursing has been rising slowly. The national sample study of registered nurses (NSSRN) is the gold standard used to identify nurse supply. This study from State Boards of Nursing of licensed nurses found in 2008 that $9.8 \%$ of nurses who were employed and graduated after 2000 were men but those licensed before 2000 had $6.2 \%$ men. Overall they found $6.6 \%$ of all registered nurses were men ${ }^{[1]}$ this is up from $5.8 \%$ in $2004{ }^{[2]}$. The US Census in 2008 found that $5.5 \%$ of people identifying themselves as professional nurses or nurses were men ${ }^{[3]}$. The National League for Nursing reports increasing numbers of 
men graduating from schools of nursing with $10 \%$ in 2003 rising to $12 \%$ in 2007 and $15 \%$ in $2011^{[4]}$. This may be a more accurate view of the current pool of nurses who are men since many nurses keep their licenses after retirement or leaving the profession. What motivates men to enter nursing? Once they become nurses do they find job satisfaction?

\section{Background}

\section{Motivation}

Two primary answers to why men become nurses have been examined - intrinsic factors of helping others and providing caring services or extrinsic factors, such as career opportunities, job stability and pay.

Several researchers have found men who choose nursing state their primary motivation is the same as women's "to help others" ${ }^{[5-10]}$. Like women, men entering nursing as their first professional career emphasize intrinsic factors such as desire to help others, caring, interesting work, community respect, sense of achievement, working closely with people, contributing to society, mentally challenging work, and self validation ${ }^{[5-8]}$. Synder ${ }^{[11]}$ agrees but found in qualitative interviews that men defined helping others more broadly than women who saw helping to be one on one patient care; they saw helping others to include both patient care and giving back to society, helping the nursing profession as a whole to be recognized as an integral part of the health care system, becoming a researcher or other broader nursing role. Men also spoke less of caring and compassion.

Raines ${ }^{[12]}$ found that second career nursing students emphasized intrinsic motivations, along with being valuable to the profession due to skills from previous work experiences. In fact, some men point out that when changing careers later in life it is more important to do something meaningful that you like to do ${ }^{[11]}$. Marsland ${ }^{[13]}$ found that male nurses were less likely than female nurses to have had nursing as a first choice of career but as a convenient choice or a second career. Men also spoke of applying their experience in other fields to enhance their nursing careers.

Supporting extrinsic motivation for choosing nursing, male nurses do report considering extrinsic factors more than female nurses ${ }^{[5,9,14]}$. Extrinsic factors reported include flexible hours, salary, future earning potential, opportunity for advancement, autonomy, flexibility to leave and return to the workforce, employment security and travel opportunities. Other researchers have found that men believe they bring some special skills to nursing, including greater physical strength, camaraderie, stronger interest in improving working conditions, and less emotion ${ }^{[11]}$. Despite these considerations, Hagstom \& Kjellberg ${ }^{[15]}$ found that both men and women in nursing put altruism first but men had higher scores at graduation for extrinsic factors. Over the first four years of work women nurses increased their value on extrinsic factors such as benefits and career and influence resulting in no gender differences. The early differences may relate to men entering nursing after working in other positions and the male socialization to be a breadwinner and support a family. Both of these would increase motivation to examine the extrinsic factors as well as intrinsic ones when making a career choice. LaRocco ${ }^{[16]}$ found men in nursing reported career satisfaction and considered nursing a genderless profession with a focus on caring for the patient.

\section{Career choices}

Nursing has several avenues for entrance with people entering at different life stages. Those that enter nursing as a first career may do so by preference or by what some refer to as convenience. Others enter as a second career after success, often in a male dominated field. Simpson's ${ }^{[17]}$ ethnographic study found men tended to follow three career paths into nursing: career seekers who actively chose nursing, career finders who entered by convenience and lastly, settlers, who left a male dominated career and settled into nursing. This she found was parallel for men who entered two other female dominated professions: teachers and librarians. Another researcher found some enter nursing through "the trap door" of falling into it after losing another male dominated job ${ }^{[18]}$. Snyder ${ }^{[11]}$ questions the trap door category since nursing requires specific education and licensing. Rather, she found that the majority of men in nursing chose it after work in an entry level health related field that required minimal post secondary education such as a Emergency Medical Technician or 
phlebotomist or military medic where they discovered nursing demanded technical skill and decision making rather than just "following physician orders and being a handmaiden". They choose nursing as their professional career for both helping others and career advancement to a profession that offered more variety and opportunities for advancement. This view is supported by the NSSRN 2008 study showing most men enter nursing after some work experience and, on average, first licensure for men is 4 years older than women ${ }^{[1]}$.

\section{Sexual stereotyping of men in nursing}

The written history of nursing now is almost exclusively a history of women's accomplishments. The many contributions of male nurses are not included, perpetuating that male nurses are anomalies; with history providing no male role models for male students ${ }^{[17,19,20]}$. The fact that men in nursing are referred to as male nurses is a reflection of the norm that women are nurses ${ }^{[11]}$. There have been several attempts to diversify the public's beliefs about norms for becoming a nurse. The one often cited as having the most impact was the Johnson and Johnson campaign that began in the 1990s to recruit men and minorities ${ }^{[21]}$. Men entering Nursing have stated that job satisfaction is one reason motivating them, yet they are often labeled as lacking ambition, low achiever, or gay ${ }^{[22-24]}$. Men repeatedly report more experiences of sexual stereotyping by staff nurses than by faculty or in the community ${ }^{[25]}$. Stereotypes such as this require men to overcome these beliefs held by many nurses when they are students, again as nurses and in the community ${ }^{[26]}$.

\section{J ob satisfaction}

The nursing shortage is expected to continue to worsen by 2020 with an expected need of over 100,000 new nursing positions. With the improvement in the economy, more nurses will retire, more nurses will take part-time positions and with the U.S. health-care laws going into effect in $2014^{[27]}$. The current nursing shortage has magnified attempts to recruit and retain nurses. Employers tend to look at monetary rewards, which may only partially aid recruitment or retention. The three most important factors found in a recent study were autonomy, pay, and social interaction at work ${ }^{[28]}$. Patients often rate their hospital stay in accordance with their nursing care and an unhappy nurse may result in an unsatisfied customer ${ }^{[29]}$. Recent changes in Medicare payment have begun to include patient satisfaction as a factor in payment ${ }^{[30]}$.

In a study addressing gender differences in job satisfaction, predictors of nurse job satisfaction were not found to vary by gender, but the importance of predictors differed for men and women ${ }^{[31]}$. Men reported having attractive nursing opportunities nearby and not experiencing job aggression as the most important job satisfiers. Another recent study looked at men in nursing and other occupations and found that men in nursing reported being satisfied with their work, and had similar levels of social support and life satisfaction as other men ${ }^{[32]}$. They also reported less overall conflict between work and family relations than other samples of men but that when it did occur it was a significant job dis-satisfier. Simpson ${ }^{[17]}$ found that role strain was a common stressor for many men in female dominant careers due to the tension between gender role and career identity. Some male nurses reported coping by identifying themselves not as a nurse but as their specialty such as "emergency room nurse" or Nurse Anesthetist to accent the male, highly technical and demanding features of the job while avoiding mention of the feminine image of nursing ${ }^{[17]}$. The negative impact of role strain is offset when men experience high social support from managers, co-workers, family and friends ${ }^{[32]}$.

Overall, the studies of work satisfaction of men in nursing have had mixed results. The NSSRN in 2008 found men earn more than women in nursing but are also more likely to leave due to salary ${ }^{[33]}$ and are more likely to be employed outside of nursing ${ }^{[34]}$. Other, studies have found no difference in job satisfaction by gender ${ }^{[31,35]}$. Another found that men in nursing were as satisfied with their work as men in general ${ }^{[32]}$. No studies of difference in job satisfaction or career development by career path to choose nursing were found.

\section{Purpose}

This study examines if job satisfaction differs for men who choose nursing as their first choice of career, as a convenience after exploring other options, or as a second career. 


\section{Methods}

\subsection{Research design}

Permission to conduct the study was obtained from the Institutional Review Board. Inclusion criteria were to be a male Registered Nurse. All male registered nurses were invited to participate in the study online. The online survey was placed on the website for Male Nurse Magazine. The website has a national and international readership and has approximately 8,000 to 12,000 hits per day. The survey was advertised free of charge on the websites of Male Nurse Magazine, The American Assembly of Men in Nursing, and in print at Advance for Nurses.

\section{I nstrument}

Job satisfaction was examined using Lester's ${ }^{[36]}$ Teacher Job Satisfaction Questionnaire with six subscales that measured satisfaction with supervision, colleagues, pay, advancement, security, and opportunity. Lester's questionnaire was used as it was developed to better understand the issue of job satisfaction in a predominately female profession. Additional questions regarding pay, security, and advancement were developed from the research literature. Demographic questions and questions on the path of entry into nursing were also included. Men were asked to check their path of entry: "I entered nursing directly from high school"; "I entered college with a major other than nursing and entered due to availability, convenience, or lack of being able to find a job"; or "nursing is a second career for me." Operational definitions for area of work and path of entry were supplied and respondents self-selected. The respondents were invited to complete a survey with 36 questions using a six-point Likert scale which offered the following choices that ranged from 1 - strongly disagree to 6 - strongly agree. No neutral option was offered. Content validity was established for each of the items by utilizing a jury of seven male registered nurses from the following areas: two from medical/surgical units, three from specialty units, and two from administration. A factor analysis was performed to verify the validity for each subscale of job satisfaction (supervision, colleagues, pay, advancement, security, and opportunity) studied. After factor analysis, items in each variable were subjected to reliability tests. Cronbach alpha coefficients for factors ranged from .63 to .90 - supervision- .90 , colleagues- .77 , pay- .68 , advancement- .63 , security- .75 , and opportunity- .64 .

Analysis was done using Statistical Package for the Social Sciences 13 (SPSS) descriptive statistics and analysis of variance (ANOVA) for significance of differences. The level of significance was $p \leq .05$.

\section{Results}

Two hundred and forty nine usable surveys were returned from throughout the world with a majority from the United States. The population consisted of self-reported male registered nurses that were primarily experienced (10 or more years of practice), in their 40s or more, with a bachelor of science in nursing (BSN) or higher degree and practicing in a specialty area or as an administrator. Over $50 \%$ were second career with 10.71 average years in nursing, more likely to be ADN prepared (29.1\%) and more likely to be in specialty practice (64.9\%) (see Table 1 for demographics).

An ANOVA was used to report the difference in years of experience by method of entry (choice, convenience or second career). Both those who chose nursing or entered by convenience had more years of experience than second degree men ( $p$ $\leq .0001)$. Path of entry and area of work were significantly related $(p \leq .0001)$. Those who chose nursing first were the most likely to be in administrative roles and the most likely to have a higher degree. Those who entered nursing by convenience had higher degrees similar to second career nurses and were more likely to be administrators like the choosers. Second career nurses were more likely to be in clinical practice, specifically technical areas of practice. The men were also asked an open-ended question regarding career plans for the future five years (see Table 2) and, as expected from their ages, $16.1 \%-18.7 \%$ were planning to retire in all three groups. Of those planning to continue to work, $16.7 \%-26.7 \%$ expected to stay in the same position. The choosers were least likely to think they would stay in the same position (16.7\%), most likely to return for a higher degree. and none planned to leave nursing. The convenience group was most likely to stay 
in the same position (26.7\%), least likely to return for a higher degree and most likely to leave nursing (14.3\%). The second career nurses were likely to work in clinical positions but $6 \%$ planned to leave.

Table 1. Frequency and Percent Demographics by Path for Entry

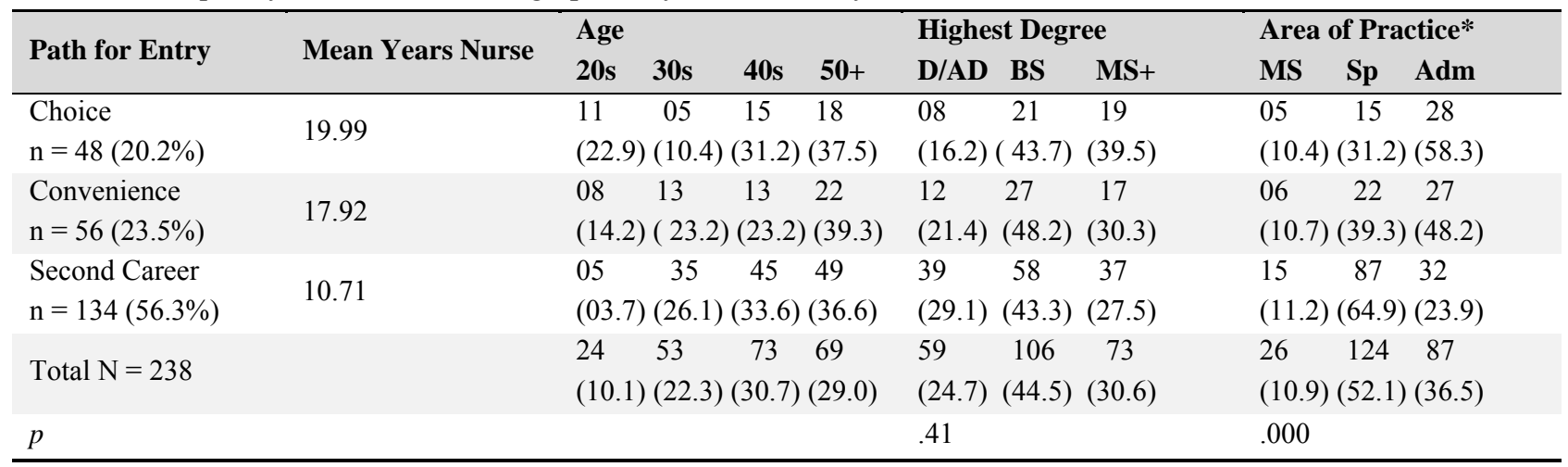

*MS = medical surgical hospital practice, $\mathrm{Sp}=$ Specialty Practice in any location, Adm= Administrator in any location

Table 2. Frequency and Percent Plan for Work Positions in Five Years by Path for Entry

\begin{tabular}{|c|c|c|c|c|c|c|c|c|}
\hline Path for Entry & $\begin{array}{l}\text { Same } \\
\text { Position }\end{array}$ & $\begin{array}{l}\text { Return to } \\
\text { school }\end{array}$ & Admin & APN & $\begin{array}{l}\text { Teach } \\
\text { Nursing }\end{array}$ & Retire & $\begin{array}{l}\text { Other } \\
\text { Left }\end{array}$ & Unsure \\
\hline Choice & 8 & 9 & 8 & 7 & 6 & 8 & \multirow{2}{*}{0} & 2 \\
\hline $\mathrm{n}=48(20.2 \%)$ & $16.7 \%$ & $18.7 \%$ & $16.7 \%$ & $14.6 \%$ & $12.5 \%$ & $16.7 \%$ & & $4.2 \%$ \\
\hline Convenience & 15 & 6 & 9 & 5 & 2 & 9 & 8 & 3 \\
\hline $\mathrm{n}=56(23.5 \%)$ & $26.7 \%$ & $10.7 \%$ & $16.1 \%$ & $8.9 \%$ & $3.6 \%$ & $16.1 \%$ & $14.3 \%$ & $5.4 \%$ \\
\hline Second Career & 33 & 21 & 19 & 18 & 7 & 25 & 8 & 3 \\
\hline $\mathrm{n}=134(56.3 \%)$ & $24.6 \%$ & $15.7 \%$ & $14.2 \%$ & 13.4 & $5.2 \%$ & $18.7 \%$ & $6.0 \%$ & $2.2 \%$ \\
\hline \multirow{2}{*}{ Total $\mathrm{N}=238$} & 56 & 36 & 36 & 30 & 15 & 42 & 16 & 8 \\
\hline & $23.5 \%$ & $15.1 \%$ & $15.1 \%$ & $12.6 \%$ & $6.3 \%$ & $17.6 \%$ & $6.7 \%$ & $3.4 \%$ \\
\hline
\end{tabular}

No significant differences were found using ANOVA by career path entry for any of the six dimensions of job satisfaction (supervision, colleagues, pay, advancement, security, and opportunity) as shown in Table 3. Participants were most positive about supervision and somewhat positive about colleagues, pay, security, and opportunity. Their lowest level of satisfaction was with future advancement. Each item was then evaluated for differences by career path entry through item analysis comparing the differences by pairs (choice vs. convenience, choice vs. second career, convenience vs. second career). Only two comparison pairs had significant relationships. The item asking about lasting friendships among colleagues showed a significant difference between those who entered by choice or by convenience with a $p=.004$. Choosers agreed more strongly than convenience entry men. The item asking about salary as a deciding factor in choosing nursing, showed a significant difference between those entering by choice or by convenience with a $p=.033$. Those who entered nursing by convenience agreed more strongly than choosers.

Table 3. Descriptive Statistics for Dimensions of Job Satisfaction

\begin{tabular}{llllllll}
\hline \multirow{2}{*}{ Dimension of Job Satisfaction } & & \multicolumn{2}{c}{ Choice } & & \multicolumn{2}{c}{$\begin{array}{c}\text { Convenience } \\
\mathbf{n = 5 6}\end{array}$} & \multicolumn{3}{l}{$\begin{array}{l}\text { Second Career } \\
\mathbf{n = 1 3 4}\end{array}$} \\
\cline { 3 - 8 } & Range & Mean & S.D. & Mean & S.D. & Mean & S.D. \\
\hline Supervision & $8-48$ & 34.84 & 9.08 & 35.86 & 7.61 & 35.47 & 9.34 \\
Colleagues & $6-36$ & 21.63 & 4.72 & 20.11 & 4.82 & 20.97 & 4.57 \\
Pay & $6-36$ & 21.15 & 5.98 & 22.15 & 6.00 & 21.71 & 5.74 \\
Advancement & $4-24$ & 12.91 & 4.66 & 12.01 & 4.54 & 11.80 & 4.13 \\
Security & $6-36$ & 24.48 & 4.13 & 25.27 & 4.46 & 24.74 & 5.03 \\
Opportunity & $4-24$ & 16.33 & 4.08 & 16.90 & 3.89 & 16.97 & 3.65 \\
\hline
\end{tabular}




\section{Limitations}

This online survey attracted a sample that had more higher education degrees than most nurses with $75.1 \%$ having a BSN or graduate degree. The $2008 \mathrm{NSSRN}^{[1]}$ found that men and women registered nurses are equally likely to have a Bachelors and Masters highest degree in nursing (approximately 50\%); adding those with a Masters degree outside of Nursing, 7\% more men had masters degrees. Limitation of the study was the sample was biased by those using the Internet and willing to participate. They also had an average of over 10 years or more experience that may have contributed to the high percentages in administrative positions.

\section{Discussion and implications}

This study was consistent with others ${ }^{[37,38]}$ who found men across all entry paths to nursing were more likely to be working in other specialties in practice than Medical Surgical nursing. Second career nurses were significantly more likely to work in other specialty units. They were also the most likely to plan to remain in direct patient care in the same position or as an advanced practice nurse and the least likely to plan to become an administrator.

The choosers and convenience career path men had similar years of experience but the choosers reported holding more graduate degrees and administrative positions. They were also more likely to agree they had lasting friendships among colleagues and less likely to report having salary as a deciding factor in career choice. These findings may reflect their early decision to enter nursing. They were also most likely to plan to become faculty. The convenience nurses appeared to be less committed to nursing with $14.3 \%$ planning to leave and the highest percentage planning to be in the same position in 5 years (26.7\%). This is consistent with the definition that they did not specifically choose nursing as their first choice.

The choosers and convenience entry nurses had the most experience since they did not enter after another career. The findings of this study support the literatures ${ }^{[12,17]}$ which find the positions of men varied by method of entry with second career male nurses preferring to remain working closely with their patients putting more weight on the intrinsic rewards.

Perhaps the increases in men entering nursing reflect a reduction in barriers for men to enter nursing. This may also reflect societal changes that are reducing the traditional differences in male and female roles ${ }^{[39]}$. Despite the steady but slow growth in the percent of men in nursing, its image remains overwhelmingly female. This survey does not identify substantial differences in job satisfaction between men who enter through different career paths or substantial differences with other studies of male and female nurses.

\section{Recruitment and retention}

In looking at recruiting men into Schools of Nursing, their similar motivation for intrinsic satisfaction from helping others fits current practices. Our findings indicate that male oriented recruitment efforts should additionally include more attention to extrinsic factors such as information on leadership through specialized practice, and advancement opportunities in administration or specialized advanced practice using male role examples ${ }^{[8,9]}$. Snyder ${ }^{[1]}$ also found many men only consider nursing after being introduced through a lower level job in health care or knowing someone who shares a realistic description of the work. Recruitment efforts should include opportunities for high school or middle school boys to be exposed to real nurses in roles that reflect male strengths by shadowing nurses in specialties such as Emergency Nursing or Critical Care or attending day camps such as Scrubs Camp that are staffed my male nurses ${ }^{[40]}$. Recruitment also needs to target men who are seeking second careers with more meaningful work or those in lower level health care jobs such as technicians seeking careers with advancement opportunities. Currently men entering nursing as a second-career are the largest male entry group ${ }^{[7]}$. Recent recruitment efforts have included more inclusive male and minority images and audiences.

Once admitted, schools need to be more sensitive to creating male friendly environments including curriculum inclusion, provision for connection to male role models, and clinical preparation to overcome gender issues in the work place ${ }^{[25]}$. 
When recruiting and retaining male nurses, employers should plan to address gender specific dis-satisfiers such as role strain due to stereotyping resulting in patients being more likely to be aggressive ${ }^{[42]}$ or peers using them as "muscle" ${ }^{[6]}$ or viewing them as homosexual ${ }^{[24]}$. Strategies might include promoting networking with other men in the workplace, sensitivity to safety issues, and emphasis on male nurse's professional contributions. One author recommended diversity training with staff nurses to become more aware of their own sexual stereotypes impacting their relationships with men in nursing ${ }^{[25]}$. Lou, Yu and Chen ${ }^{[43]}$ recommended that professional development of men in nursing should emphasize development of communication and emotional skills to supplement their other strengths and utilization of strategies to increase professional empowerment leading to career advancement. Strategies might include participation in committees and councils and offering tuition reimbursement for attaining higher degrees and positions in advanced practice or management.

As their career opportunities have widened and the value of a diversified workforce to more clearly match patient populations has been recognized, nursing has begun strategies to recruit men and minorities. Both educators and employers need to create environments where men and minorities feel welcome and empowered to contribute all their talents.

\section{References}

[1] US Department of Health and Human Services (USDHHS) (2010). Health Resources and Services Administration. The registered nurse population: Findings from the 2008 National Sample Survey of Registered Nurses. www.hbpr.hrsa.gov/healthworkforce/rnsurvey.2008.html. Retrieved June 29, 2011.

[2] US Department of Health and Human Services (USDHHS) (2006) Health Resources and Services Administration. The registered nurse population: Findings from the 2004 National Sample Survey of Registered Nurses. www.hhpr.hrsa.gov/healthworkforce/rnsurvey. 2004. html. Retrieved June 29, 2011

[3] Auerbach, D.I, Staiger, D.O, Muench, U. Buerhaus, P.I. The nursing workforce: A comparison of three national surveys. Nursing Economics. 2012; 30(5): 253-260.

[4] National League for Nursing 2012 Annual Survey of Schools of Nursing Fall 2011 Retrieved from www.nln.or/research/slides/index.htm January 28, 2013.

[5] Boughn, S. Women and men choose nursing. Nursing and Health Care Perspectives. 2001; 22 (1): 14-19.

[6] Whitlock, M \& Leonard, L. Stepping outside the stereotype. A pilot study of the motivations and experiences of males in the nursing profession. Journal of Nursing Management. 2003; 11: 242-249. http://dx.doi.org/10.1046/j.1365-2834.2003.00379.x

[7] Hodes, B. Men in nursing study. Hodes Research. Available from http://aamn.org . 2005; June 29, 2011.

[8] Hart, K.A. What do men in nursing really think? Nursing. 2005; 35(11): 46-8. PMid:16280923 http://dx.doi.org/10.1097/00152193-200511000-00045

[9] Zysberg, L. \& Berry, D.M. Gender and student's vocational choices in entering the field of nursing. Nursing Outlook. 2005; 53(4): 193-198. PMid:16115512 http://dx.doi.org/10.1016/j.outlook.2005.05.001

[10] Mullan, B \& Harrison, J. Male and female nursing applicant's attitudes and expectations towards their future careers in nursing. Journal of Research in Nursing. 2008; 13: 527-539. http://dx.doi.org/10.1177/1744987107085500

[11] Snyder, K.A. Insider knowledge and male nurses: How men become registered nurses. Research in Society and Health Care. 2011; 29: 21-41. http://dx.doi.org/10.1108/S0275-4959(2011)0000029004

[12] Raines, D. A. What attracts second degree students to a career in nursing? Online Journal of Issues in Nursing. 2011; 16(1) www.nursingworld.com Retrieved July 1. 2011.

[13] Marsland, L. \& Murrelis, T. Pursuing a career in nursing: differences between men and women qualifying as a registered general nurse. Journal of Nursing Management. 1996; 4(4): 231-241. PMid:8868711 http://dx.doi.org/10.1111/j.1365-2834.1996.tb00056.x

[14] Meadus, R.J. \& Twomey, J.C. Men in nursing: making the right choice. Canadian Nurse. 2007; 103(2): 13-16.

[15] Hagstrom, T. \& Kjellberg, A. Stability and change in work values among male and female nurses and engineers. Scandinavian Journal of Psychology. 2007; 48: 143-151. PMid:17430367 http://dx.doi.org/10.1111/j.1467-9450.2007.00576.x

[16] LaRocco, S. A. A grounded theory study of socializing men into nursing. Journal of Men's Studies. 2007 ; 15 (2): $120-129$. Simpson, R. Men in non-traditional occupations: Career entry, career orientation and experience of role strain. Gender, Work and Organization. 2005; 12 (4): 363-380. 
[17] Williams, L.S. \& Villemez, W. J. Seeker and finders: Male entry and exit in female dominated jobs. In C.L. Williams, (Ed.) Doing women's work: Men in non-traditional occupations, 1993; pp. 64-90. London: Sage.

[18] LaRocco, S.A. Recruitment and retention of men in nursing. In CE O’Lynn \& R.E. Tranburger (Eds) Men in Nursing History, Challenges and Opportunities. New York: Springer Publishing Company, 2007.

[19] Evans, J. Men nurses: a historical and feminist perspective. Journal of Advanced Nursing. 2004; 47(3): 321-328. PMid:15238127 http://dx.doi.org/10.1111/j.1365-2648.2004.03096.x

[20] Johnson \& Johnson Discover Nursing: Men in nursing website http://www.discovernursing.com.

[21] Armstrong, F. Men in nursing. Australian Nursing Journal. 2002; 9(11):24-26.

[22] Cullen, L.T., August, M, Brown, D.E., Ellen, H., Gill, D. Rubiner, B. I want your job lady. Time. 2003; 161(19): 55-56.

[23] Harding, T. The construction of men who are nurses as gay. Journal of Advanced Nursing. 2007; 60(61): 636-644. PMid:18039250 http://dx.doi.org/10.1111/j.1365-2648.2007.04447.x

[24] Cude, G. \& Winfrey, K. The hidden barrier Gender bias: Fact or Fiction? Nursing for Women's Health. 2007; 11(3): $255-264$.

[25] Kouta, C \& Kaite, C.F. Gender discrimination and nursing: a literature review. Journal of Professional Nursing. 2011; 27(1): 59-63.

[26] Staiger, DO. Auerbach, DI, Buerhaus, PI Registered Nurse labor supply and the recession - Are we in a bubble? New England Journal of Medicine. 2012; 366: 16.

[27] Curtis, EA. Job satisfaction: A survey of nurses in the Republic of Ireland. International Nursing Review. 2007 ; 54: $92-99$.

[28] Kutney-Lee, A, McHugh, M.D., Sloane, D.M., Climiotti, J.P., Flynn, L., Neff, D.F. Aiken, L.H. Nursing: a key to patient satisfaction. Health Affairs. 2009; 28(4): w669-w677.

[29] Chin, M.H. Patient experience now linked to doctor's payment. Medical Ethics Advisor. 2012; 28(19): 102.

[30] Andrews, M.E., Stewart, N.J., Morgan, D.G. \& D’Arcy, C. More alike than different: A comparison of male and female RNs in rural and remote Canada. Journal of Nursing Management. 2011. Early View doi:10.1111/j.1365-2834.2011.01195.x011.

[31] Rochlen, A.B., Good, G.E., \& Carver, T.A. Predictors of gender-related barriers, work, and life satisfaction among men in nursing. Psychology of Men and Masculinity.2009; 10(1): 44-56. http://dx.doi.org/10.1037/a0013291

[32] Rajapaksa, S. \& Rothstein, W. Factors that influence decisions of men and women nurses to leave nursing. Nursing Forum. 2009; 44(3): 195-206.

[33] Black, L., Spetz, J, Harrington, C. Nurses who do not nurse: Factors that predict non-nursing work in the U.S. nursing labor market. Nursing Economic\$. 2010; 28(4): 245-254.

[34] Curtis, E.A. The effect of biographical variables on job satisfaction among nurses. The British Journal of Nursing. 2008; 17(3): 174-180.

[35] Lester, P. E. Teacher job satisfaction questionnaire. In Lester, P. and Bishop, L. K. (Eds). Handbook of Tests and Measurement in Education and the Social Sciences. 1984; 147-150. Lanham, Md.: Scarecrow Press.

[36] Lindsay, S. Gendering work: The masculinization of nurse anesthesia. Canadian Journal of Sociology. 2007; 32(4): 429-448. http://dx.doi.org/10.2307/20460664

[37] Armstrong, F. Not just women's business: men in nursing. Australian Nursing Journal. 2002; 9(11): 24-26.

[38] Judge, T.A. \& Livingston, B.A. Is the gap more than gender? A longitudinal analysis of gender, gender role orientation and earnings. Journal of Applied Psychology. 2008; 93(5): 994-1012. PMid:18808221 http://dx.doi.org/10.1037/0021-9010.93.5.994

[39] Sayman, D.M. "These aren't as risqué as the firemen" Calendars as recruiting campaigns for men in nursing. Journal of Philosophy and History of Education. 2010; 60: 61-66.

[40] Glacki-Smith, J., Juarez, A. M., \& Boyett, L. Violence against nurses working in US emergency departments. Journal of Nursing Administration. 2009; 39: (7/8): 340-349. http://dx.doi.org/10.1097/NNA.0b013e3181ae97db

[41] Lou, J., Yu, H. \& Chen, S. Factors affecting the career development of male nurses: a structural equation model. Journal of Advanced Nursing. 2010; 66(4): 900-910. http://dx.doi.org/10.1111/j.1365-2648.2010.05264.x 